\title{
Legislación cooperativa mundial. Tendencias y perspectivas en América Latina*
}

\author{
Dr. José M. ${ }^{a}$ Montolio \\ Consultor cooperativo
}

Sumario: I. La cooperativa, institución tan de alcance mundial como de realización local. II. El actual entorno de globalización y crisis. III. Respuestas legislativas: 3.1. Visión de conjunto. 3.2. Evolución. 3.3. Recomendaciones y normas supranacionales e internacionales. IV. Tendencias y perspectivas, en particular, en América Latina.

Resumen: En este artículo se hace hincapié en la dimensión local e internacional de las cooperativas en nuestro mundo globalizado y se proponen los cambios legislativos más acordes para el desarrollo de las cooperativas en América Latina.

Palabras clave: Propuestas de cambios legislativos en América Latina.

Abstract: This paper highlights the local and international dimension of cooperatives in today's globalised world and proposes some legislative changes to favour development of cooperatives in Latin America.

Key words: Proposals for legislative changes in Latin America.

* Exposición dispuesta para el Congreso Internacional «Hacia nuevas tendencias del cooperativismo» organizado por el Instituto Panameño Autónomo Cooperativo (IPACOOP) en conmemoración de su trigésimo aniversario de actividad. Panamá, 28 y 29 de octubre de 2010. 
Es opinión común que el cooperativismo, en sentido moderno, tiene como referencia histórica la segunda mitad del siglo xIX y en concreto la experiencia Rochdale (1844). De forma análoga se tiene como primera norma específica la ley británica «Industrial and Provident Partneship Act» (IPSA) de 1852. Como todos los convencionalismos, sean éstos recibidos sin necesidad de mayor dedicación: sabemos por lo demás que experiencias de esta naturaleza han acompañado al género humano, aquí y allá, desde tiempos inmemoriales. La bibliografía es abundante. ${ }^{1}$

Lo que se pretende en este momento constatar es que, una vez más, se hace realidad tangible el viejo aforismo latino «ius oritur facto». Es decir, que toda regulación jurídica tiene como antecedente necesario un hecho social y que precisamente es éste, junto con su relevancia en el contexto de la sociedad de que se trate, el que justifica aquella.

Del mismo modo quiere señalarse que cuando a lo largo de los años asistimos a sucesivas actualizaciones, reformas o sustituciones normativas no se está haciendo otra cosa que dar respuesta a un mismo hecho en lo que constituye su realidad cambiante de la mano del curso del tiempo. ${ }^{2}$ Las sociedades y sus requerimientos son todo menos estáticas.

El hecho social cooperativo, la concreta sociedad en se produce y, desde luego, el contexto circunstancial y temporal en que tiene lugar constituyen las premisas del tema normativo que tenemos encomendado. A su desarrollo nos comprometemos seguidamente con sujeción al sumario que ha quedado enunciado.

\section{La cooperativa, institución tan de alcance mundial como de realización local}

No puede negarse que, fueren cuales fueren sus precedentes en las distintas regiones y países, el fenómeno cooperativo devino mundial.

1 Por todas las referencias aquí y ahora, las clásicas obras de G. Mladenatz: Historia de las doctrinas cooperativas, Intercoop, Buenos Aires, 1969 (la primera edición francesa data de 1933, PUF) y del matrimonio Drimer: Las cooperativas: fundamentos, historia y doctrina, también en Intercoop, Buenos Aires, 1982 (hay otras ediciones).

2 El profesor R. Altamira, considerado padre de la Historia del Derecho en España, en el inicio de su Historia del Derecho español, Lib. Gral. de Victoriano Suárez, Madrid, 1903, reflexionaba al hilo de la evolución del Derecho como un proceso que acompañaba a la propia imperfección del hombre «que no alcanza a realizar de una vez la plenitud de ninguna de sus propiedades». 
Sus manifestaciones resultan también del todo comparables y se basan en un mismo fundamento: la autoayuda mutualista, la suma de esfuerzos entre quienes más lo necesitaban. El «operare cum» - actuar conjuntamente, en comunidad y en la misma dirección- se percibió como inexcusable en muchos sectores de la actividad humana. Así los "ayllus» precolombinos, las «misericordias» portuguesas, las «lecherías» en los países de la Europa central, las «endechas» y figuras afines de trabajo rural en común en el norte de nuestro país, los «pósitos» o graneros comunales de inspiración árabe, las «cofradías» de socorros mutuales y otras muchas manifestaciones aquí y allá. Todos estos antecedentes, en los que conviven elementos de mutualidad, cooperación y acción solidaria, fueron conformando un núcleo «genérico» de cooperación. ${ }^{3}$

Desde luego que, desde la perspectiva más actual, la cooperación es inseparable de la evolución - cuando no revolución- del siglo XIX, con la desaparición de anteriores estructuras de mediación entre individuo y Estado y la necesidad de una articulación social también nueva. El maquinismo, la progresiva conversión de población rural en trabajadores atraídos por los centros fabriles de las ciudades, las sucesivas oleadas de "pauperismo», el asociacionismo obrero, el fervor de idearios socialistas y el innegable peso de la doctrina social de la Iglesia, han de considerarse precursores.

Ciertamente que, a lo largo de la Historia, las cooperativas han sido perseguidas, ignoradas y también apoyadas por los poderes públicos. Ahora bien, el hecho cierto es que hoy encontramos fórmulas cooperativas en todos los rincones del planeta y en todas las manifestaciones de la actividad humana. Conforme a las ya añosas estadísticas de Naciones Unidas (1994), a punto de actualización, cerca de la mitad de la población mundial participa en actividades cooperativas (consumo, ahorro, seguros...) y más de 800 millones de personas son miembros activos de empresas cooperativas que generan

3 Además de muchas otras fuentes, por atenernos a la presente convocatoria puede acudirse a mis trabajos Legislación cooperativa en América Latina. Situación, Derecho comparado y proceso de armonización, Ministerio de Trabajo, Madrid, 1990, donde se ofrecen concretas referencias al continente americano; Legislación cooperativa en la Unión Europea, Ministerio de Trabajo, Madrid, 2000 (2. ${ }^{a}$ ed.), donde se da una visión particularizada de los países de la UE —entonces de 15 Estados miembros - y con una perspectiva más local y/o sectorial a «Las cooperativas en España: evolución y perspectivas», Anuario de Estudios Cooperativos, Univ. Deusto, Bilbao, 1992, y «Contexto y significado de la primera Ley de cooperativas de España (1931)», dentro del vol. colectivo La república de los trabajadores. La segunda república y el mundo del trabajo, Fund. Largo Caballero, Madrid, 2006. 
más de 100 millones de empleos. Esto explica, por ejemplo, que a pesar de las distancias y diferencias, en Canadá una de cada tres personas sea cooperativista; que en Kenya lo sea una de cada cinco y que en Europa solamente la banca cooperativa proporcione 700.000 empleos fijos.

Si pusiéramos la vista en términos de producción, se estima, dicho sea también a título de ejemplo, que en Uruguay el 90\% de la leche se procesa por cooperativas, porcentaje todavía mayor en Noruega o Finlandia, país en que las cooperativas llegan a canalizar el 75\% de todos los productos alimenticios. Brasil participa en un porcentaje similar en la producción de trigo y más de la mitad del vino y del aceite de oliva español es de origen cooperativo.

Ninguno de estos datos es menor. No es de extrañar, por tanto, que la Organización de Naciones Unidas, consciente de la realidad y potencialidad del cooperativismo haya declarado el año 2012 (Resolución de la 64. ${ }^{a}$ Asamblea General A/RES/64/136, de 18 de diciembre de 2009) como "Año Internacional de las Cooperativas». El propósito es claro: reconocimiento de las cooperativas, promover el cooperativismo, extender el conocimiento de su significado y alentar a los gobiernos a establecer leyes y normas en su favor.

En definitiva y como se ha señalado de forma concisa a la par que sumamente expresiva, ${ }^{4}$ "las cooperativas son hijas de la necesidad» aquí y en cualquier otro lugar del mundo. De una necesidad genérica, en principio, y de unas necesidades muy concretas en cada caso y situación. De esta forma se explica la cooperativa como institución mundial con la obligada particularización en cada caso atendiendo las especificidades locales a las que inexcusablemente debe responder. Un transplante o la importación sin más de instituciones y técnicas casi con toda seguridad abocará al fracaso.

Podría concluirse de esta manera en que, desde un sustrato ideológico compartido — resumámoslo ahora bajo la mención de la «identidad cooperativa» como compendio de sus valores y principios- se ha hecho universal una vía de interacción social y de empresa económica propia, sin perjuicio de que sus distintas concreciones afloren notorias asimetrías. Pensemos, por ejemplo, en la naturalización de las cooperativas como asociación o como sociedad, en la distinta dimensión del voto singular o plural, en la admisión o veto de la financiación externa, etc.

4 Rosembuj, T.: Presentación del «Boletín 2006 de la Asociación Internacional de Derecho Cooperativo», rubricado Globalización y cooperativismo, Univ. Deusto, Bilbao. 
Es decir, que no cabe aplicar sin mayores consideraciones metodología o legislación ajena sin estar prioritariamente a los requerimientos locales, al igual que no cabe establecer, sin más, comparaciones normativas. ${ }^{5}$ Necesariamente ha de atenderse la historia, las necesidades presentes, el contexto, la cultura social de cada país. Cuestión bien distinta es que se conozcan y se valoren aquellas experiencias y criterios que puedan aportarse, más si cabe si proceden de organizaciones afines.

\section{El actual entorno de globalización y crisis}

Tampoco se precisan demasiadas palabras para tomar contacto con el significado y consecuencias prácticas del fenómeno de la «globalización» en que vivimos. La globalización, trasunto de la interdependencia de todos los países y regiones del planeta, ofrece como proceso múltiples facetas - no sólo la crucial de la economía - sino también y decididamente muchas otras de alcance social, tecnológico y cultural. El símil más frecuente es el de la proyección de la «aldea global» mcluhaniana propuesta ya en los años '60 del pasado siglo.

En efecto, las telecomunicaciones - y con ellas la información - alcanzan los lugares más insospechados; los recursos financieros se mueven con facilidad pasmosa; jamás se ha experimentado una apertura de mercados como la actual; las empresas deslocalizan sus instalaciones con la celeridad del beneficio inmediato. En fin el «viejo orden» parece llamado a su fin.

El fenómeno en sí, que en principio no cabría reputar de forma simplista bueno o malo, ${ }^{6}$ tanto puede ayudar a países en vías de desarrollo como acarrear serias amenazas como consecuencia de la apreciable carencia de sensibilidad social de su planteamiento. ${ }^{7}$ Ahora bien,

5 Recomendaba el profesor Altamira: op. cit., p. 52, que a la hora de analizar y establecer comparaciones entre Ordenamientos para comprender sus instituciones se tuvieran siempre en cuenta «las legislaciones y costumbres de los pueblos y de sus épocas sucesivas, para ver sus semejanzas, sus diferencias, las relaciones y mutuos influjos».

6 El entonces Secretario General de las Naciones Unidas, el ghanés K. AnNAN se refería al fenómeno de la globalización dentro de la denominada Cumbre del Milenio (septiembre de 2000) comparándolo con un tres de alta velocidad que "sólo se detiene allí donde los andenes están a su altura».

7 El prestigioso sociólogo francés A. Touraine, al hilo de su libro «Un nuevo paradigma: comprender el mundo de hoy», señalaba en una entrevista publicada en la revista Cuadernos de Información y Comunicación (CIC), vol. 11/2006 editada por la Univ. Complutense de Madrid. que «la globalización significa antes que nada una desvinculación extrema entre actores e instituciones. Es decir, por debajo del nivel mundial económico hay un fuerte debilitamiento de lo social...». 
la opción de ignorarlo, encerrándose dentro de las fronteras no parece la más razonable.

Nadie puede negar que el fenómeno implica evidentes amenazas para las condiciones de trabajo, para la sostenibilidad y preservación del medio ambiente, a la par que un innegable incremento el poder de las grandes corporaciones y de su incidencia sobre los gobiernos: ejemplos sobran. Del mismo modo, tampoco hemos de ser ciegos ante las oportunidades de desarrollo que ofrece a muchos países hasta el momento excluidos de esta posibilidad. El reto está en cómo dar una respuesta adecuada y todo apunta a que, hoy por hoy, no se ha logrado.

La prueba más evidente puede venir dada por actual «crisis» de la economía mundial arrastrada por el desenfreno de los movimientos financieros, la extrema desregulación y la ineficacia de los mecanismos de control. Desde finales de 2007 los Bancos centrales de las principales economías occidentales hubieron de facilitar sucesivas inyecciones de liquidez a la banca con la finalidad confesada de impedir una crisis comparable a la del '29 que la interdependencia propia de la globalización hacía temer. Los casos del holding financiero "Lehman», de la amenaza de bancarrota de las entidades especializadas en el crédito hipotecario a las familias «Fannie Mae» y «Freddie Mac» («Federal National Mortgage Association» y «Federal Home Loan Mortgage Corporation», respectivamente) de la obligada nacionalización del «Royal Bank of Scotland», entre otros de renombre, pueden considerarse la parte visible del iceberg de una crisis que especialmente ha hecho presa en los llamados países desarrollados. Los altos precios de las materias primas desatados al mismo tiempo, situándose a la cabeza el del petróleo, han contribuido a este poco alentador panorama.

Así las cosas, la desaceleración de la economía de los EEUU caminó pareja con la fuerte contracción de Japón en el segundo semestre de 2008, junto con la padecida por Alemania, país que se tiene como motor de la zona euro. España, por no ir más lejos, ha alcanzado una tasa de desempleo cercana al $20 \%$. Desde una perspectiva más próxima si cabe, México se vio privado en buena medida de remesas procedentes de la emigración que, como es sabido, constituyen su segunda fuente de ingresos tras el petróleo. En Argentina, los desequilibrios de la balanza comercial condujeron a tener que prescindir significativamente de productos siderúrgicos con todo lo que ello implica. El cataclismo de financiación y empleo ha llegado hasta las hacía poco boyantes economías petroleras del Golfo con lo que significa de devolución de emigrantes a sus países de origen, sobre todo en África y Asia. 
La preocupación por la seguridad financiera es evidente y la reciente reunión del Grupo de Gobernadores de Bancos centrales (septiembre de 2010), bautizado como Basilea III por la ciudad suiza que la acogió, ha llevado al $7 \%$ el nivel de reservas de la banca establecido con anterioridad en el 2\%. El G-20 (Toronto, Canadá, junio de 2010), por su parte, no parece haber logrado grandes acuerdo. La desconfianza se ha generalizado. La recuperación se aventura lenta y esta situación es más preocupante si cabe desde la perspectiva del empleo.

La también reciente Conferencia sobre Empleo OIT-FMI (Oslo, Noruega, septiembre de 2010) 8 baraja la cifra de la pérdida de más de 200 millones de puestos de trabajo directamente con causa en la crisis. Se llega a hablar de toda una generación de jóvenes que han ultimado su formación y que no han de encontrar ocupación. Indudablemente son tiempos difíciles por mucho que todas las generaciones piensen lo mismo de los que les toca vivir.

Sin perjuicio de las puntualizaciones hechas, afortunadamente para el conjunto de esta región, América Latina ha demostrado, a juicio de los expertos, una notable resistencia ante la crisis. ${ }^{9}$ Economías como las de Brasil, Colombia, Chile y Perú evidencian una fuerte actividad. Panamá ha mejorado varios puestos en competitividad -situándose próximo al $50 .^{\circ}$ del conjunto mundial- conforme al Foro Económico Mundial (WEF). Tal es así que el Banco Mundial vaticina un crecimiento de conjunto del orden del $6 \%$, con mejoras en casos como el de Brasil ${ }^{10}$ que llegaría al $7 \%$ y relativo empeoramiento en otros, cual Perú que continuaría en un nada despreciable 5\%. La única excepción vendría constituida quizá por Venezuela para cuya economía se llega a vaticinar, incluso, un crecimiento negativo. Mención especial merece, sin duda, el reciente proceso abierto en Cuba. A la anunciada y muy significativa reducción de empleo en el sector público — se alcanza a leer cifras del orden de medio millón- se une una nueva perspectiva de economía privada con la promoción de empleos por cuenta propia. Las dificultades son evidentes, formativas, fi-

8 Se la considera como el «Breton Woods» del empleo en comparación con lo que aquella Conferencia supuso para el sistema monetario mundial tras la II Gran Guerra.

9 Por lo que a la región centroamericana se refiere, parece así despejado el «rumbo incierto» que se advertía analizando la segunda mitad del siglo xx y los años de bonanza con que se cerrara la década de los '70. Vid. Lizcano, F.: Desarrollo socioeconómico de América Central en la segunda mitad del siglo xx. Univ. Autónoma del Estado, México, 2000.

10 Cabeza del grupo de países «BRICs» (Brasil, Rusia, India y China) caracterizados por la potencialidad de su enorme población, territorio y recursos naturales. 
nancieras, de acceso a maquinaria y materias primas. En este punto es seguro que tanto los instrumentos de trabajo asociado - cooperativas e instituciones comparables - como los sistemas de auto empleo han de resultar de utilidad. ${ }^{11}$

En definitiva, éste es el contexto en que han de desenvolverse las cooperativas, ya que el marco de globalización y crisis es común. En el mismo han de demostrar una vez más su potencialidad. En este planteamiento, qué duda cabe, la colaboración legislativa tiene su lugar por mucho que no se trate de un factor aislado y, quizá, ni siquiera principal.

\section{Respuestas legislativas}

Volvemos sobre el planteamiento inicial: hasta aquí el hecho social y la respuesta cooperativa. Corresponde ahora un somero análisis de las iniciativas legislativas.

\subsection{Visión de conjunto ${ }^{12}$}

La primera gran división que cabría hacer al respecto vendría determinada por la situación de aquellos países carentes en absoluto, en un momento dado, de legislación en materia de cooperativas en relación con aquellos otros que, desde tiempo atrás, gozaron de ella. Dentro del primer grupo se encontraban mayoritariamente países de África y de Asia por el contrario de lo que sucedía en América y Europa.

En estas últimas regiones, la legislación sobre cooperativas empezó a tomar carta de naturaleza en la segunda mitad del siglo XIX tanto como legislación especial como incluida en los Códigos o en otras leyes de mayor ámbito, vg.: sociedades o asociaciones. Si la IPSA británica data de 1852, los Códigos comerciales de Argentina (1882) y de México (1889) contenían ya regulación de las cooperativas, al igual que sucediera en Alemania con la Ley de 1889 (fiel trasunto de la Ley "Schulze» de 1867) y que, desde luego con modificaciones sigue en vigor), en Francia con la Ley de sociedades de capital variable de 1867,

11 Se ofrece aquí una referencia a las Leyes españolas 4/1997, de 24 de marzo, de Sociedades Laborales, y 20/2007, de 11 de julio, del Estatuto del trabajo autónomo.

12 Por la facilidad que proporciona la información compendiada, a pesar de su inevitable desactualización, y desde luego por la bibliografía especializada que se recoge, me remito a los trabajos de esta naturaleza reseñados en la nota 3. 
en Portugal con la comparable Ley del mismo año y España con el Código de 1885 y antes con la legislación sobre asociaciones. Caso señero es el que representa Venezuela que inaugura en el continente americano la técnica de la legislación especial mediante la Ley de asociaciones cooperativas de 1910 mientras otras legislaciones de la región mantuvieron la técnica de la codificación, vg.: los Códigos de comercio de El Salvador de 1904, Colombia de 1912 y Panamá de 1916, aunque aquella acabaría por prosperar, vg.: Leyes de Chile (1925), Argentina (1926) y México (1927). En suma, se asentó la tendencia de una legislación «local».

La perspectiva opuesta viene ofrecida por aquellos países de los continentes africano y asiático, normalmente en dependencia colonial, en los cuales la legislación cooperativa fue importada directamente desde la metrópoli. La conocida como Ley modelo de 1946 («Model Co-operative Societies Ordinance») propuesta por la British Colonial Office y que se implantó con mayor o menor éxito en las distintas colonias, no sólo de aquellas regiones sino también del Caribe y del Pacífico Sur. Destacó por su aceptación la India, probablemente por contar con el precedente de la normativa de 1904 relativa a las cooperativas tuteladas por el Estado y dio lugar a la conocida como "Classical British-Indian Pattern of Co-operation» que se proyectara al resto de países bajo su influencia. Algunas de las regulaciones contenidas en aquellos modelos pasaron luego a las legislaciones nacionales, si bien adaptados a las exigencias locales, vg.: Tanzania (1968), Zambia (1970), Sudán (1970 y actual de 1999) y Kenya (1966 y actual de 1997). ${ }^{13}$

Esta iniciativa fue seguida de cerca por Francia mediante un Decreto de 1955, exclusivo para sus colonias, y que venía a actualizar el régimen de unas sociedades de ayuda mutua tuteladas también por el Estado. Buena parte de sus disposiciones pasaron a los nuevos países tras la independencia, bien es cierto que atentos a la realidad de los mismos, vg.: Senegal (1960), Costa de Marfil (1966) y Camerún (1969).

13 Da cuenta el prof. Münkner: La reglamentación legal de la pre-cooperativa. Un aporte a la reglamentación de formas de organización pre-cooperativas en países en desarrollo, Fund. Friedrich-Ebert, Bonn 1981, nota 114, de cómo, por ejemplo en Tanzania la normativa complementaria de la Ley asigna concretas tareas al comité de fundación - asesorado por un funcionario especializado- y entre ellas establecer qué tipo de cooperativa se pretende, en qué número de socios se piensa como ideal, cuales son las bases económicas y empresariales del proyecto, cuales deben ser las determinaciones esenciales de los estatutos de la entidad, es decir, ajustar el proyecto a la realidad concreta y a sus circunstancias. 
Des estas experiencias indudablemente cabe extraer, cuando poco, dos conclusiones. La primera de neto alcance de técnica legislativa: primacía del sistema de ley especial para regulación de las cooperativas - cuando no varias leyes en atención a su objeto- frente a cualquier otro, bien de codificación o de inserción en legislación de mayor ámbito. La segunda, abandono de las leyes modelo a favor de la particularización local, por mucho que elementos de aquella resulten asumidos por las normas que han venido a sustituirlas.

\subsection{Evolución}

Efectivamente la evolución de la legislación cooperativa aquí y allá ha discurrido por los cauces técnicos de «lex specialis», cierto que como en casi todos los aspectos sujetos a regulación jurídica, quizá por la propia complejidad de nuestras sociedades. Este parece ser uno de los signos de nuestro tiempo; la especialización hasta lo impensable.

En el ámbito de América Latina dentro incluso de las propias cooperativas se ha particularizado la regulación de determinados sectores. De forma unitaria, Argentina mantiene la Ley de 1973 continuando así la andadura que iniciara en 1926. Bolivia, por su parte, cuenta con la ya veterana Ley General de Sociedades Cooperativas de 1958 completando la regulación con la Ley de 13 de diciembre de 1996 para el sector del ahorro y crédito a la par que las cooperativas mineras obtienen regulación propia desde el Código de la minería aprobado por Ley de 17 de marzo de 1997. Uruguay acoge también la misma técnica de ley especial mediante la Ley de 24 de octubre de 2008, emprendiendo un camino de unificación legislativa al derogar la regulación separada de cooperativas en general (1946) frente a las agrarias (1984) y las de trabajo asociado (2004). Muchos otros países de la región — vg.: Perú (1990), México, Paraguay y Puerto Rico (1994), Panamá (1997), Venezuela (2001), Chile (2003), Costa Rica y Nicaragua (2004) .... han actualizado su legislación desde la década de los ' 90 hasta la actualidad y otros estudian la reforma de la suya, ahora bien, acogiendo con carácter general la anunciada técnica de la legislación especial complementada en muchos casos con la previsión de disposiciones específicas para determinados sectores de actividad.

No otro es el caso de la legislación en Europa donde, desde luego, impera también la técnica de la «lex specialis» pero donde también la «ley única» constituye excepción frente a un abrumador 
panorama de extrema fragmentación en la cual intervienen no sólo la actividad de la cooperativa sino, como se dirá, la geografía. En efecto, la regulación francesa o italiana abarca un abigarrado abanico (cooperativas, agrarias, de vivienda, de vivienda pero para alquiler a precio moderado, de crédito, de trabajo asociado, pequeñas cooperativas...) que solamente pueden ser consideradas dentro de una identidad unitaria bajo la perspectiva del Estatuto de la cooperación (1947) en el caso de Francia y de la «Ley Basevi» (también de 1947) en el caso de Italia. Por supuesto y en lo que a su naturalización jurídica se refiere el abanico también es bien diverso: mercantiles en Alemania, Bélgica o Luxemburgo así como en los países del Norte; civiles o asociaciones en el caso de Italia u Holanda; mutuales y en parte "sui generis» en el Reino Unido, etc...

Bien, el caso español es paradigmático. Además de la vigente Ley estatal (1999) y las que con ese ámbito regulan el tratamiento tributario de las cooperativas (1990) y el crédito cooperativo (1989), 15 de las 17 Comunidades Autónomas en las que se estructura el Estado surgido de la vigente Constitución (1978) tienen cuando poco una Ley propia en materia de cooperativas. No es de extrañar que la situación haya levantado críticas del todo razonables. ${ }^{14}$

La evolución normativa así sucintamente acotada sí deja trazas de un cierto distanciamiento entre las tendencias en Europa y las que parecen advertirse en el continente americano. En el caso de Europa, como tendremos ocasión de comprobar, si hay una orientación sobre todas las demás es la aproximación de la regulación de la «sociedad» cooperativa al régimen general de las «sociedades» de capital. De ahí muchas de las herramientas de las que se viene dotando a las cooperativas desde la reforma alemana de 1973 y las leyes de modernización francesa e italiana de 1992: mejora de los instrumentos financieros, admisión de socios no usuarios, aceptación del voto plural ponderado... En el caso de América Latina se sigue primando lo que la doctrina de-

14 E. Gadea, F. Sacristán y C. Vargas: Régimen jurídico de la sociedad cooperativa del siglo XXı. Realidad actual y propuestas de reforma, Dikynson, Madrid, 2009, pp. 61/62, dejan constancia de la «... compleja y criticable situación legislativa del Derecho cooperativo español ...La doctrina de forma mayoritaria ... coincide en que la fragmentación de nuestra Legislación cooperativa es perjudicial para una sociedad que tiene que competir con instituciones capitalistas que tienen una regulación uniforme y difícilmente explicable ante el mandato de fomentar las sociedades cooperativas que impone el art. 129.2 de la CE. E, igualmente, en que la existencia de tantas leyes de cooperativas en España va en contra de la propia jurídica.» Poco aporta confesar que desde hace bastantes años sostenemos la misma opinión, pero así es. 
nomina "principismo» 15 en el sentido de un quizá excesivo apego a la ortodoxia identitaria y distanciamiento de la perspectiva empresarial de la cooperativa.

Quizá no esté de más detenerse, también con brevedad, en este punto. Veamos. Tras otras modificaciones de relieve cual la dirigida a someter las cooperativas a auditoría, el consistente movimiento cooperativo alemán, a finales de la década de los '60, se planteó su situación de estancamiento en el contexto empresarial y las reformas legislativas que entendía insoslayables. Este fue el origen de la actualización legislativa de 1973 que consideramos referente de futuro. Cuatro fueron los puntos fuertes de reflexión:

- No todos los socios participan en igual medida de la cooperativa, lógico parece entonces que a quien más se arriesga se reconozca un mayor poder de decisión, eso sí, siempre de forma ponderada.

- Si se precisa financiación y ésta ha de proceder preferentemente de los socios, deben establecerse unos tipos de interés razonables, que incentive las aportaciones a capital.

- Ante la necesidad de competir en el mercado, las cooperativas no pueden ser discriminadas y por tanto habrán de aceptarse las operaciones con terceros. Cierto es que tal prohibición sólo subsistía ya entonces para las cooperativas de crédito.

- Por la misma causa y con el fin de ganar agilidad empresarial conviene incrementar las facultades de los administradores, ahora bien bajo un régimen de responsabilidad y con sujeción al control permanente del Consejo de vigilancia, delegado permanente de la Asamblea general.

Las reformas o Leyes de modernización francesa e italiana de 1992 puede decirse que hicieron énfasis en aspectos análogos. De esta manera se aceptan socios no usuarios entendiendo por tales a quienes no participan en la actividad cooperativizada pero acuden a su financiación. Se les concede el derecho político de voto si bien en su conjunto no han de superar 1/3 (Italia) un 35\% (Francia) del total de la entidad. Del mismo modo se permiten nuevos instrumentos de financiación (partes sociales de interés preferencial, certificados cooperati-

15 Cracogna, D.: «La legislación cooperativa en el mundo de hoy», exposición presentada en el Seminario de legislación cooperativa de Uruguay, noviembre de 2001. El autor añade a este «principismo» otros factores, en especial, el paternalismo e intervencionismo desde los poderse públicos. 
vos de inversión o acciones de participación cooperativa que alcanzan a ser negociables y no vienen limitados a los socios, etc...) buscando el fortalecimiento financiero de las cooperativas. Estas medidas, siempre potestativas, ${ }^{16}$ tienen el contrapeso en el caso de Italia de los llamados «fondos mutualistas» que se nutren del 3\% de los beneficios de cada entidad y son gestionados por las entidades de integración con el fin de promoción del cooperativismo.

$Y$ ya puestos en esta tesitura de las reformas en Europa, no ha de ocultarse que algo similar ocurre en España sobre todo en cuanto a la aceptación de socios no usuarios (adheridos, colaboradores ... dependiendo de la legislación), admisión de toda una pluralidad de nuevos instrumentos de financiación (participaciones especiales, títulos participativos, obligaciones...), incremento de la posibilidad de operaciones con terceros (un supuesto de normalidad alcanzaría por ejemplo el $50 \%$ en cooperativas agrarias) y exigencia de un menor número de socios para la fundación de la cooperativa (vg.: sólo 3 en la legislación general y ésta es la tónica).

En todo ello no resulta ajeno, además del curso de los tiempos, la influencia de normas o recomendaciones internacionales, como veremos, en los casos que acaban de acotarse muy en particular el Reglamento de la Sociedad Cooperativa Europea de 2003.

\subsection{Recomendaciones y normas supranacionales e internacionales}

Cuanto acaba de exponerse nos da idea del polimorfismo con que se manifiesta el tratamiento de las cooperativas en los diferentes ordenamientos $y$, si podemos decirlo despasionadamente, un cierto movimiento centrífugo en relación con los principios identitarios que comúnmente aceptamos como tales. ${ }^{17}$

16 En el análisis monográfico «Une réforme en profondeur de la loi du 10 septembre 1947», Rev. des études coopératives, mutualistes et associatives (RECMA), n. os 4445 (1992). B. Piot insistía en que el propósito no era otro que facilitar a las cooperativas una buena caja de herramientas («une bien fournie boîte d'outils») para evitar su situación de inferioridad en un mercado cada vez más competitivo.

17 Referencia obligada hoy a la «Declaración de Identidad Cooperativa» adoptada por el Congreso centenario de la Alianza Cooperativa Internacional, Manchester (Reino Unido) 1995 bien conocida y cuyo texto se recoge en numerosísimas fuentes. 


\section{$\S A$}

Si intentamos una cierta sistemática cronológica, que además nos lleva a América Latina, la primera referencia ha de hacerse a la denominada "Ley marco para las Cooperativas de América Latina» aprobada en el VIII Congreso continental de la Organización de las Cooperativas de América (OCA) que tuvo lugar en Bogotá en el mes de noviembre de 1988. Por su puesto que, como toda realización humana, la «Ley Marco» es susceptible de crítica. Ahora bien lo que no podrá achacársele es que no haya sido fruto de una elevada participación de sectores cooperativos, expertos y representantes de administraciones.

Precedieron a su elaboración los trabajos de tres Congresos continentales en la materia (Mérida, Venezuela 1969; San Juan de Puerto Rico 1976 y Rosario, Argentina 1986), articulándose a raíz de los dos Seminarios internacionales celebrados en Santa Cruz de la Sierra (Bolivia) en los años 1987 y 1988. Además del apoyo de la Organización a que se debe, el proyecto fue acogido por el Parlamento Andino y por el Parlamento Latinoamericano. Ambas instituciones lo recomendaron precisamente bajo la naturaleza que le resulta más propia: no la de una norma supranacional con vocación de incorporarse uniformemente a los distintos Ordenamientos nacionales, sino de una recomendación - desde el consenso del cooperativismo del continente y para las cooperativas del mismo- que pudiera servir a la actualización legislativa de la región en materia de cooperativas. ${ }^{18}$

El proyecto que, como se ha avanzado, ya tuvo su repercusión en varios Ordenamientos como ya se ha avanzado en ésta y otras ocasiones, ${ }^{19}$ fue actualizado en 2008 (San José, Costa Rica) con el pro-

18 Ha de tenerse en cuenta que, así como OCA mantiene la condición de ONG, los citados Parlamentos son Organismos regionales integrados por representaciones parlamentarias de los Estados miembros signatarios de los correspondientes Tratados, suscrito aquel en La Paz (Bolivia) en 1979 y formalizado éste Lima (Perú) en 1987. En la actualidad en el Parlamento Andino concurren hoy Bolivia, Colombia, Ecuador y Perú, al haberse apartado del mismo Chile y Venezuela, y tiene su sede en Bogotá (Colombia). El Parlamento Latinoamericano («Parlatino») da cabida al conjunto de países del continente y tiene su sede en Panamá. Entre las misiones de una y otra institución están la de deliberar conjuntamente en asuntos de interés común, la defensa de la igualdad de los pueblos y de las instituciones democráticas, la colaboración y el fomento de la integración latinoamericana. No gozan de potestad normativa propiamente dicha sino de capacidad de recomendación.

19 Montolio, J.M. ${ }^{\text {a: }}$ "Excurso sobre características determinantes (aspectos sustantivos) de la legislación latinoamericana en materia de cooperativas», dentro del vol. colectivo Las Cooperativas en Iberoamérica y España. Realidad y legislación, Univ. Católica de Ávila (España), 2002. 
tagonismo de $\mathrm{ACl}$-Américas y tras los trabajos que hubieron de precederle. ${ }^{20}$

Como características principales del proyecto pueden señalarse las siguientes:

- Ofrece una vocación de norma general haciendo abstracción de sectores específicos de actividad que con frecuencia requieren legislación propia. En este punto el proyecto sólo se hace eco (Capítulo $X$ ) de una sucinta propuesta de regulación especial para cooperativas de trabajo asociado, crédito, vivienda, escolares y aquellas cooperativas constituidas en el extranjero (arts. 91 y ss.).

- Asume (Capítulo I) los principios de la identidad cooperativa y mantiene el voto único por socio (art. 5), la limitación de intereses a las aportaciones (art. 41) y la irrepartibilidad de las reservas (art. 44).

No es de pasar por alto que se abre una modesta posibilidad de operaciones con terceros —en determinadas circunstanciassujetando sus resultados a régimen separado (art. 8) y se prevé la posibilidad de asociaciones con empresas de distinta naturaleza (art. 12) aunque no así la eventual transformación de la cooperativa.

- Abre la posibilidad de financiación por parte de socios no usuarios si bien limitada a entidades sin ánimo de lucro, organismos cooperativos o gubernamentales, estableciendo el techo de sus derechos políticos en el 30\% del total de la cooperativa y la limitación de ocupar un porcentaje superior en los órganos de la misma (art. 21) si bien prevé también la posibilidad de que las cooperativas asuman todas las formas de pasivo y emitan obligaciones suscribibles por socios o terceros (art. 46).

- Mantiene la estructura ordinaria de órgano de dirección (Asamblea), administración (Consejo de administración) y control (Junta de vigilancia), a la par que posibilita la existencia de una gerencia profesionalizada y responsable.

- Propone la conveniencia de integración de cooperativas en entidades de grado superior, a las cuales podría encomendarse incluso actividades de supervisión, así de la existencia de un Organismo o Instituto estatal específico en materia cooperativa.

20 Vid.: Cracogna, D.: "Nueva versión de la Ley Marco para las Cooperativas de América Latina», Rev. Jurídica de Economía Social y Cooperativa n. ${ }^{\circ} 20$, Ciriec-España, Valencia 2009, pp. 183 y ss. El texto del proyecto fue publicado en 2009 en San José (Costa Rica) por ACl-Américas, ISBN 878-9968-13-048-6. 
— Finalmente, propugna la posibilidad de revisión jurisdiccional de las decisiones de la autoridad de aplicación, a fin de contribuir a la transparencia del sistema.

Puede apreciarse que la tendencia de asumir mecanismos hasta hace poco exclusivos de las sociedades de capital tienen su acogida en la propuesta. No será un caso aislado aunque su alcance resulte distinto.

\section{$\S B$}

Con el fin de no interrumpir la secuencia relativa a la región, aunque se desatienda el criterio cronológico, hacemos seguidamente una referencia a la propuesta MERCOSUR/PM/ANT.NORMA 01/2009 circunscrita como es natural a los países que integran esta entidad supranacional. ${ }^{21} \mathrm{El}$ texto recoge los trabajos y propuesta final de la Reunión Especializada de Cooperativas del Mercosur (RECM). ${ }^{22}$

El objetivo principal de la propuesta viene constituido por las cooperativas transfronterizas, cooperativas con socios de distintos Estados parte, bien fuere de primer o superior grado y que se denominará «Cooperativa del Mercosur». Esta nueva vía, conforme al proyecto, no excluye la posibilidad de cualquier otra forma de integración o colaboración, en especial las que se pudieran lograr a través de sociedades comerciales. La previsión es que las legislaciones de los Estados miembros adicionen a su legislación una sección reconociendo tales cooperativas.

De este planteamiento se deducen las siguientes características para las «Cooperativas del Mercosur»:

- Han de asociar miembros de al menos dos Estados parte y aquel en que se ubiquen representará al menos el $51 \%$ de los socios y del capital suscrito.

- Todos los socios disfrutarán de los mismos derechos con independencia de su nacionalidad y los Estados parte reconocerán

21 Argentina, Brasil, Paraguay y Uruguay — Venezuela se mantiene como «asociado» al no haber obtenido la aquiescencia de la totalidad de los Estados parte para acceder a tal condición-. Tienen la consideración de asociados Bolivia, Chile, Colombia, Ecuador y Perú y, la de observadores, México y Nicaragua.

22 Este foro especializado encuentra referente último en el art. 1 del Tratado de Asunción por el que se crea el MERCOSUR y que solemniza el compromiso de los Estados miembros de armonizar sus legislaciones con el fin de fortalecer el proceso de integración. Sobre los trabajos del RECM puede verse la publicación colectiva Régimen legal de las cooperativas en los países del MERCOSUR, Intercoop, Buenos Aires, 2003. Hay más ediciones. 
plenamente estas cooperativas, en régimen de reciprocidad, una vez que acrediten su constitución legal.

- Las reglas de constitución, funcionamiento, supervisión, disolución y liquidación se sujetarán a las disposiciones comunes en la materia con la necesaria adecuación a la naturaleza específica de la entidad.

- Los casos de eventual conflicto se solventarán ante la autoridad de aplicación y los órganos jurisdiccionales del Estado donde la cooperativa se hallare domiciliada.

La regulación que se propone aparece, pues, en extremo prudente, acorde con el propósito de lograr una armonización lo que nunca es tarea fácil. Quizá por ello deja de lado formas de constitución, cual la fusión de cooperativas de distinta nacionalidad preexistentes, cuestión que, sin embargo y como se expondrá, sí se aborda en otros ámbitos aunque se desdibuje el propósito armonizador.

\section{$\S C$}

La Organización Internacional del Trabajo no ha sido ajena al ámbito de las empresas en común desde muchos años atrás y tampoco, en concreto, de las cooperativas. Baste recordar, en este momento y entre otros ejemplos, su apoyo a la "Ley Marco» a que se ha hecho referencia y su trascendental Resolución 127/1966 sobre cooperativas en países en vías de desarrollo, todo un hito entonces y precedente inmediato de la vigente Recomendación 193//2002 relativa a la promoción de cooperativas aprobada por su 90. ${ }^{a}$ Conferencia General.

No tratándose de un texto articulado, es claro que la recomendación se mueve en el ámbito de las propuestas y consideraciones. No obstante de su texto principal y, sin lugar a dudas de su anexo, pueden extraerse las siguientes características:

- La recomendación no se dirige ya en exclusiva a los países en vías de desarrollo sino que lo hace con carácter general.

- Sus propuestas no se limitan a los gobiernos sino también a las organizaciones de empleadores y de trabajadores así como a las posibilidades de cooperación internacional.

- En su definición de cooperativa se hace eco plenamente de la formulación $\mathrm{ACl}$ y de sus principios. Enuncia en primer término la finalidad de la cooperativa de "satisfacer necesidades y aspiraciones económicas» sin olvidar seguidamente la mención de aquellas otras «sociales o culturales» siempre a través de una «empresa de propiedad conjunta y de gestión democrática». 
Desde esta perspectiva asume el principio democrático máximo de "un hombre un voto» en las cooperativas de primer grado que, sin embargo, podría modularse en las de grado superior. ${ }^{23}$

- Mantiene la limitación de intereses a las aportaciones de los socios si bien abre la posibilidad de financiación externa siempre y cuando no ponga en riesgo la autonomía y gobierno democrático de la cooperativa.

Con las limitaciones dichas en cuanto que la formulación de principios no encierra los riesgos de su concreta articulación, lo cierto es que de la Recomendación 193 abre nuevos horizontes en la actualización de las legislaciones cooperativas. A nuestro entender no es de hacer de menos aquella esclarecedora mención que versionamos a nuestro modo en el sentido de que las cooperativas no sólo son empresas económicas ¡pero también!24

\section{$\S D$}

Podemos incluir ahora una referencia también breve, no ya a una propuesta o recomendación, sino a una norma supranacional. Nos referimos al Reglamento (CE) 1435/2003, del Consejo, de 22 de julio de $2003^{25}$ por el que finalmente y tras años de debate se aprobó el Estatuto de la Sociedad Cooperativa Europea (ESCE). Digamos de entrada que la entrada en vigor de dicho Estatuto no significa que las cooperativas de todos los Estados miembros — en la actualidad 2726 - se rijan por una sola norma ¡nada más lejos de la realidad! Tampoco que las legislaciones de dichos Estados hayan de armonizar su legislación cooperativa conforme a dicho Reglamento. Lo que significa el ESCE es que los cooperativistas de dichos Estados disponen de un nuevo instrumento a

23 El tenor literal de la recomendación en este punto es como sigue: «En las cooperativas de primer grado, los socios tienen iguales derechos de voto (un socio, un voto) y las cooperativas de otros grados están también organizadas de forma democrática».

24 Snaith, I.: "Co-operative Law in the UK: The Current Reforms and Prospects», dentro del vol. colectivo Droit Comparé del Cooperatives Européennes, Ed. Larcier, Faculté de Droit, d'Économie et de Finance de l'Université du Luxembourg, Bruxelles (Belgique), 2009, pp. 15 y ss. La cita textual es así, p. 22: «However, most of the company law reforms in the late 2oth century were to make life easier for business. Industrial and provident societies are business and they were not included. As a result they suffered real or perceived competitive disadvantage».

25 Diario Oficial de la Unión Europea (DOUE) 270/1, de 18 de agosto de 2003.

26 Alemania, Austria, Bélgica, Bulgaria, Chequia, Chipre, Dinamarca, Eslovaquia, Eslovenia, España, Estonia, Finlandia, Francia, Grecia, Holanda, Hungría, Irlanda, Italia, Letonia, Lituania, Luxemburgo, Malta, Polonia, Portugal, Reino Unido, Rumania y Suecia. 
su alcance para organizar cooperativas transnacionales. Por lo demás, el ESCE ni armoniza ni suplanta las legislaciones internas, ${ }^{27}$ se trata de una herramienta legal de nueva creación que en la proyección supranacional a que responde convive con las distintas regulaciones nacionales.

Sucede en el contexto comunitario europeo que el art. 58 del Tratado fundacional de la Comunidad Económica (Roma, 1957) incluía expresamente en la definición de «sociedad» a las cooperativas. El instrumento para "armonizar», es decir, lograr una verdadera aproximación de las legislaciones de los Estados miembros venía constituido por las Directivas». Las directivas obligan a lograr un resultado dentro de un plazo determinado. Para lograr este objetivo han de adecuarse los respectivos Ordenamientos internos.

En el ámbito del Derecho de sociedades, desde 1968 se venían aprobando Directivas para armonizar la publicidad de los diferentes actos societarios, asegurar la posición de socios y terceros, sistematizar la sistemática de cuentas, etc... De todas ellas vinieron expresamente excluidas las cooperativas quizá por la gran diversidad de regulaciones al contrario de lo que resultaba en las sociedades de capital, además de la relevancia de su respectiva implantación. Tal es así que la promulgación del Estatuto de la Sociedad Anónima Europea $(\mathrm{SE})^{28}$ se logró con mucha mayor facilidad que el relativo a la Cooperativa (SCE).

Situado así el ESCE, como instrumento potestativo a disposición de los cooperativistas que quieran promover una nueva cooperativa con socios al menos de dos Estados miembros o fusionar en una SCE cooperativas de al menos dos Estados, las características de esta nueva fórmula cooperativa ${ }^{29}$ pueden resumirse así:

27 Un análisis detallado, si bien referido al proyecto, en Montolio, J.M. a.: «Estatuto Cooperativo Europeo», Rev. De Estudios Cooperativos (REVESCO), n. ${ }^{\circ 59}$, Madrid, 1991, pp. 85 y ss.

28 Reglamento (CE) 2157/2001, del Consejo, de 8 de octubre de 2001 (DOUE L 294, de 10 de noviembre).

${ }^{29}$ En este aspecto, siempre dentro del ámbito comunitario europeo, no se ponen demasiadas trabas a fórmulas de economía participada instrumentadas a través de sociedades en lo que prima sigue siendo la persona. Conocido es el concepto de «economía social» que engloba a cooperativas, mutualidades, asociaciones, sociedades laborales ... y otras entidades emparentadas. Es decir, "otra forma de hacer economía» con antecedentes en economistas del siglo XVIII (Ch. Dunoyer, A. Ott...). Como aproximación puede verse Montolio, J.M. ${ }^{\text {: }}$ "Economía social: concepto, contenido y significación en España», Rev. de Economía Social, Pública y Cooperativa, n. ${ }^{\circ} 42$, CIRIEC-España, Valencia, 2002, pp. 5 y ss. aunque, por lo demás, la bibliografía es abundante. Por reciente puede también acudirse al «Informe Toia» de la Comisión de Empleo y Asuntos Sociales del Parlamento Europeo de 21 de enero de 2009. 
- La sociedad cooperativa europea (SCE) precisa para su constitución la participación de cinco socios de al menos dos Estados miembros. Podrá constituirse también por fusión o transformación de sociedades preexistentes. En cualquier caso el domicilio de la SCE deberá fijarse dentro del territorio común.

- El capital de la SCE, con el carácter de variable, será como mínimo de 30.000 euros, dividido en participaciones que podrán ser de distinta clase y con asignación de distinta participación en los resultados. Con cargo a lose excedentes del ejercicio la SCE atenderá los retornos que acuerde la entidad así como dotará las reservas legales o estatutarias.

- Las formalidades de constitución, registro, formulación de cuentas y publicidad de los actos sociales serán las previstas en la legislación del Estado donde se fije el domicilio, extremándose las garantías de socios, acreedores y terceros, en términos comparables al común de las sociedades. En particular los actos de constitución, cambio de domicilio y disolución se publicarán en el DOUE.

- Corresponde a los socios la formulación de sus Estatutos que en todo caso darán cabida a los contenidos mínimos - por demás usuales - propios de los mismos. Las decisiones administrativas en la materia serán revisables ante los órganos judiciales.

- Se admiten socios no usuarios y de forma amplia todos los mecanismos de financiación externa y si bien el derecho político de voto se reserva a los socios de corte clásico, los socios no usuarios pueden disfrutar de un voto contingentazo al máximo previsto en los estatutos.

- Se aceptan con carácter ordinario las operaciones con terceros.

- La estructura organizativa de la SCE podrá ser de carácter «monista» (Asamblea General y Órgano de administración) propia de los países latinos o «dualista» (Asamblea General, Órgano de administración y Órgano de control) propio del sistema alemán donde la «Dirección» ejerce la administración de la entidad bajo la tutela del «Consejo de vigilancia» como delegado permanente de la Asamblea General.

- Se impone a los Estados miembros la adopción de las disposiciones adecuadas para garantizar la aplicación efectiva del ESCE. ${ }^{30}$

30 Para cumplir este mandato, en España se tramita en la actualidad ante el Congreso de los Diputados el proyecto de Ley 121/000083 (BOCG, Congreso, Serie A, n. ${ }^{\circ} 83-1$, de 23 de julio de 2010) por la que se regula la Sociedad Cooperativa Europea con domicilio en España. Como corresponde, el proyecto huye de lo estrictamente con- 
En definitiva, al igual que vemos confirmada la aceptación de muchos de los instrumentos de que se sirven las sociedades de Derecho común, se aprecia también la cautela con que se manifiestan los propósitos armonizadores.

\section{Tendencias y perspectivas, en particular, en América Latina}

Como en otros muchos aspectos del desarrollo de las sociedades, cuando se trata de las cooperativas y de su régimen jurídico no cabe hacer abstracción de las circunstancias que lo rodean. Como se ha escrito, en el Derecho cooperativo se reflejan las circunstancias económicas, sociales y políticas. ${ }^{31}$ Efectivamente así es y no en vano se ha anticipado la ineluctable particularización local de la legislación al respecto.

No obstante y en este mismo orden de consideraciones, de las experiencias y decisiones que se han acotado a lo largo de estas páginas sí que cabe identificar las tendencias y propuestas más actuales, en particular, por lo que a América Latina se refiere. Intentaremos seguidamente una sistematización por grandes rúbricas. Seguiremos para ello en buena medida, tras unas consideraciones generales, el enunciado de los principios propios de la identidad cooperativa.

Constituciones políticas. Van en aumento los textos constitucionales que incluyen un reconocimiento expreso del cooperativismo y del compromiso de apoyo por parte de los poderes públicos. Esta es una tendencia fácilmente advertible desde hace años aquí (Colombia, Costa Rica, Ecuador, México, Venezuela ...) y en Europa donde el precedente de la Constitución italiana de 1947 fue seguido por la portuguesa de 1976, tras la «revolución de los claveles» y por la española de 1978 que restableciera el marco constitucional democrático en nuestro país.

Mandatos internacionales y supranacionales. Desde Naciones Unidas y sus Organismos especializados —en concreto OIT-, la Alianza Cooperativa Internacional $(\mathrm{ACl})$ y sus Organismos regionales, los Par-

ceptual mediante su remisión al Reglamento comunitario y se ocupa de cuanto afecta a las formalidades jurídico societarias (constitución, fusión, transformación, disolución...) y registrales. Por cierto que la competencia en esta materia se atribuye al Registro Mercantil que no a los tradicionales Registros cooperativos, trayectoria centenaria que sólo se había exceptuado a través de la doble inscripción prevista para las Cooperativas de crédito.

31 Henry, H.: Guidelines for Cooperative Legislation (2nd ed), ILO, Ginebra, 2005. La cita enmarca la introducción del trabajo y a su tenor literal es: Cooperative law is a reflection of economic, social and political circumstances. 
lamentos Andino y Latinoamericano, el Mercosur, la Unión Europea, etc... las propuestas y mandatos a favor de la cooperativa constituyen una constante. Pocas políticas podrán exhibir un respaldo similar.

Identidad institucional y unidad de regulación. Todos los Ordenamientos, con directa o indirecta referencia a la $\mathrm{ACl}$, acogen los principios universales de la institución cooperativa si bien con matices que no cabe pasar por alto.

Sin perjuicio de que, por razón de la actividad, determinadas cooperativas deban obtener una regulación específica —vg.: ahorro y crédito- se renueva una corriente en contra del fraccionalismo que supone tanta división dentro del concepto unitario de cooperativa que, a la postre, es el que ha de primar.

En este punto aflora una diferencia notoria entre las posiciones que defienden la escasa relevancia del "ánimo de lucro» en las cooperativas ya que, al fin y al cabo, cuando poco pretenden la mejora económica de sus socios aparte de la de la comunidad y las que sostienen lo contrario. De ahí que la idea «societaria» que cada vez cobra mayor vigor por ejemplo en Europa se vea escasamente representada en América Latina donde prima la idea "asociativa». A ello contribuye sin duda la propia terminología de que se sirven los organismos internacionales.

Estatutos y requisitos formales. Se tiende a facilitar la formalización de cooperativas descansando en los socios una gran autonomía en la formulación de sus Estatutos y arbitrando ante eventuales decisiones opuestas de la autoridad de aplicación la posibilidad de acudir a la tutela judicial. Esta tendencia se enmarca con frecuencia en un plan de mayor ámbito a favor del conjunto de sociedades. ${ }^{32}$

Paralelamente y con el fin de contribuir a la seguridad de socios, acreedores y terceros se imponen mayores requisitos de publicidad en aquellos aspectos que revisten una trascendencia mayor, vg.: constitución, cambio de domicilio, convocatorias, formulación de cuentas, disolución ...

Libre adhesión y baja voluntaria. Muchos Ordenamientos vienen modulando también la libre adhesión en el sentido de ajustarla a la capacidad de las instalaciones de la cooperativa. Del mismo modo, sin impedir la baja voluntaria del socio, acogen mecanismos de sujetar su actividad durante un tiempo o de graduar el reembolso de aportaciones, sobre todo en aquellas cooperativas que requieren grandes compromisos financieros.

32 Vg.: Plan BEST de promoción del espíritu empresarial en la Comunidad Europea. 
Gestión democrática. La clásica formulación «un hombre, un voto» admite progresivamente una modulación a favor del reconocimiento de voto plural ponderado, en proporción a su participación en la actividad cooperativizada y normalmente contingentado hasta $1 / 3$ del total de votos de la entidad.

No es un detalle menor el hecho de que la Recomendación 193 OIT afronte una modulación de este tipo en cooperativas de grado superior. Lo verdaderamente importante es que el control responsa a criterios democráticos y resida en los socios.

Autonomía e independencia. La tendencia generalizada es la de objetivar la intervención de las distintas administraciones públicas o autoridades de aplicación, admitiendo expresamente la posibilidad de acudir ante los órganos judiciales en casos de litigio o desacuerdo.

Educación cooperativa. Este aspecto que parece consustancial con la idea cooperativa y que ha inspirado a las cooperativas desde un principio, se resiente en la práctica al igual que la constitución y dotación de una reserva especial al respecto. Probablemente sea uno más de los efectos indeseables del aludido panorama de crisis y que precisa urgente corrección.

En este punto son muy de destacar los esfuerzos y realizaciones de muchas legislaciones y administraciones del continente americano.

Cooperación entre cooperativas. El conjunto de los Ordenamientos y de las recomendaciones internacionales priman y tienden a facilitar, en general, la cooperación entre cooperativas y, en particular, los fenómenos de cooperación transfronteriza o supranacional.

Criterio empresarial. La tendencia es la de asumir muchos de los instrumentos de que están dotadas las empresas capitalistas. La razón no es otra que, sin perder la identidad esencial de la cooperativa, no han de situarse a éstas en términos de desventaja respecto a aquellas precisamente cuando las exigencias del mercado, de la obligada competitividad y del contexto de globalización y crisis hace más difícil su desarrollo. ${ }^{33}$

33 Un fenómeno de ósmosis entre cuerpos normativos de distinto objeto, vg.: el propio de las cooperativas y el dirigido al común de las empresas, se advierte en otros muchos ámbitos. Un punto de reflexión es el de la Responsabilidad Social Empresarial, RSE («Corporate Social Responsability», CSR). Las cooperativas siempre han mantenido un propósito de servicio a la comunidad, de contribución al desarrollo sostenible, en definitiva, una concepción humanista de las actividades económicas. Pues bien, se está generalizando para el conjunto de las empresas, vg.: Comunicación de la Comisión Europea CCE.COM (2002) 347 relativa a la contribución empresarial al desarrollo sostenible. 
La adopción de este criterio tiene muchas manifestaciones y entre ellas las de admitir socios "no usuarios» y la de posibilitar el acceso a recursos financieros ajenos al cuerpo social. Esta práctica cada vez más generalizada no se considera opuesta al principio de participación económica de los socios, pues los mismos continuarán siendo titulares de la parte más significativa del capital social, ni tampoco a una cierta liberalización en la extrema limitación de intereses a las aportaciones para lograr el objetivo de fortalecimiento financiero que se persigue.

Fortalecimiento de la institución. Las tareas que se han iniciado de actualización de legislaciones, de armonización de las mismas en todo lo posible, así como el resto de medidas de normalización institucional y de índole financiera han de ir presididas por el designio de fortalecer el concepto y la institución cooperativa.

En este punto ha de prestarse especial atención y extraer todo el provecho posible de la Declaración de Naciones Unidas de 2012 como Año internacional de las Cooperativas.

Contención normativa. Por último, cada vez con mayor intensidad se está oyendo una llamada a la contención normativa, a detener una producción legislativa inasumible por la ciudadanía a la par que a hacerla más fácil y comprensible.

En este punto, como ya he señalado en otras ocasiones, recuerdo siempre el ejemplo que proponía el profesor MÜNKNER en una de aquellas densas sesiones que celebrábamos en la sede de la OIT-Ginebra en 1995 sobre actualización de la Recomendación 127/1966. Ante reiterados intentos de sumar legislación a más legislación, y así hasta los más mínimos detalles, hizo la siguiente reflexión ¿recuerdan Vds. el baobab...? Se trata de ese magnífico árbol africano («adansonia digitata») de un porte majestuoso que quizá como imagen pudiéramos sustituir en esta parte del mundo por esos inmensos mangos («mangifera indica») al igual que en España por algunos de los frondosos olmos («ulmus» en sus varias especies) que aún sobreviven. Pues bien - continuó- podremos extasiarnos ante esas maravillas de la naturaleza, pero fíjense bien: hasta donde alcanza la sombra de su copa jno crece una brizna de hierba! 34

34 El citado profesor refería («Ley de cooperativas en la República Federal Alemana», Rev. de Economía Social, Pública y Cooperativa, n. ${ }^{\circ}$, CIRIEC-España, Valencia, 1898, pp. 85 y ss.) el éxito de la reforma alemana de 1973 a tres factores: no haberse basado en concepciones puramente teóricas sino en la conjunción de técnicas y experiencias de las cooperativas ya existentes; no haberse instrumentado como un programa 
Efectivamente nadie va a poner en tela de juicio la necesidad de encauzar jurídicamente una realidad social y una actividad económica cual la que significan las cooperativas. Se trata únicamente de ponderar hasta donde conviene llegar por ese camino y hasta cuanto precisan atención otros, muy en especial —aquí y ahora- los relativos a la vertiente empresarial. Seguro que la atención de ambos resulta no sólo compatible sino beneficiosa.

ideológico o partidista sino como un instrumento de organización de economías privadas y, finalmente, haber circunscrito la regulación a lo imprescindible, quedando el resto a la autodeterminación estatutaria. 